\title{
¿ABSOLUTAMENTE SIN CUIDADO?: JUAN VILANOVA Y LA POLÉMICA SOBRE EL HOMBRE TERCIARIO*
}

\author{
Jesús I. Catalá Gorgues
}

Universidad CEU Cardenal Herrera

\begin{abstract}
RESUMEN
Un tema relevante durante el período fundacional de la paleoantropología fue el postulado de la antigüedad terciaria de la humanidad. Las primeras propuestas se basaban en supuestas evidencias de industria lítica (eolitos). La cuestión se complicó con el descubrimiento de diversos fósiles humanos que fueron datados como pliocenos o incluso de mayor antigüedad. Esta polémica sobre el llamado «hombre terciario» llegó pronto a España. El paleontólogo y catedrático de la Universidad Central, Juan Vilanova y Piera, se ocupó extensamente del asunto desde perspectivas antievolucionistas. La llegada a Valencia en 1889, formando parte de la colección paleontológica donada por José Rodrigo Botet, de un esqueleto humano fósil procedente de Argentina que mostraba rasgos aparentes de primitivismo, llevó a Vilanova a reafirmarse y exponer más intensamente sus ideas sobre esta cuestión.
\end{abstract}

PALABRAS CLAVE: Evolucionismo. Paleoantropología. España. Argentina. Siglo XIX.

\section{DIDN'T IT MATTER TO HIM ABSOLUTELY?: JUAN VILANOVA AND THE CONTROVERSY ABOUT TERTIARY MAN}

\begin{abstract}
During the founding period of palaeoanthropology, the postulate about tertiary age of humankind was an outstanding subject. First proposals were based on supposed proofs about ancient lithical industry (eoliths). Some discoveries of human fossil remains complicated that issue, because they were dated as pliocene or oldest. This controversy about so-called «tertiary man» soon arrived to Spain. Juan Vilanova y Piera, palaeontologist and professor at Madrid, dealt with it from an antievolutionist point of view. When a human fossil skeleton, included in the Botet's collection, with several apparently primitive traits arrived to Valencia from Argentina, Vilanova got reasserted and exposed his ideas about this question more intensely.
\end{abstract}

KEY WORDS: Evolutionism. Palaeoanthropology. Spain. Argentina. $19^{\text {th }}$ century.

${ }^{*}$ Proyecto «Evolucionismo y los orígenes de la humanidad: la configuración de la paleoantropología como disciplina científica y su proyección en la biología española» (Ministerio de Educación y Ciencia, ref. HUM2006-04730). 


\section{INTRODUCCIÓN}

La aceptación de la naturaleza fósil de ciertos restos humanos, tras el aserto categórico de su inexistencia por Georges Cuvier en 1812, fue un largo y complejo proceso que desembocó en la articulación de la paleontología humana como disciplina científica durante el último tercio del siglo XIX. Según Pelayo, tres acontecimientos de gran relieve científico, situados a finales de la década de los cincuenta y comienzos de los sesenta de dicho siglo, decantaron la configuración de esa nueva disciplina: el descubrimiento de los restos fósiles del hombre de Neandertal, la formulación de la teoría evolutiva de Darwin y la aceptación de una antigüedad del hombre sobre la Tierra postulada previamente a partir de inferencias basadas en el descubrimiento de las industrias líticas - que extendía la presencia humana mucho más atrás de lo que las cronologías al uso habían aceptado hasta entonces ${ }^{1}$. Para algunos autores, sin embargo, no parecía suficiente retrasar la antigüedad del hombre hasta el inicio del Cuaternario geológico. De este modo, empezaron a difundirse propuestas que databan el origen de la humanidad en las etapas finales del Terciario, si no necesariamente de la propia especie Homo sapiens, si al menos de especies relacionadas, del mismo género o más habitualmente de otros géneros, antecesoras de la actual, pero en todo caso con rasgos inequívocamente humanos. De este modo, las hipótesis sobre la existencia del genéricamente llamado «hombre terciario» - hombre al menos en el sentido que se ha apuntado - se fueron abriendo paso, casi siempre en relación con otros debates sobre el origen de nuestra especie y su sometimiento a los procesos evolutivos (poligenismo, evolución lingüística, etc.) ${ }^{2}$. En este contexto, hubo numerosas propuestas que partían, realmente, de construcciones mentales, enteramente hipotéticas, y en las que la fantasía, como bien señala sin conno-

1 Pelayo, F. (2007), Controvèrsies científiques i repercussions socials de la paleontologia humana, Mètode, 53, pp. 30-36.

2 Un buen resumen sobre las primeras propuestas sobre la existencia del hombre en el Terciario y la interacción de las mismas con otras controversias sobre el origen, evolución y antigüedad de nuestra especie en Pelayo, F. (1999), Ciencia y creencia en España durante el siglo XIX, Madrid, CSIC, pp. 255-267. Aunque sea a partir de evidencias fósiles obtenidas y estudiadas posteriormente a la época que nos ocupa, conviene recordar que hoy en día la datación terciaria de la familia Hominidae no ofrece dudas para el género Australopithecus, y es posible que incluso las especies más antiguas del género Homo correspondan al Plioceno; v., por ejemplo, AGUSTí, J. (1994a), La evolución y sus metáforas. Una perspectiva paleobiológica, Barcelona, Tusquets, pp. 170-180 y Agustí, J. (1994b), Fósiles, genes y teorías, Barcelona, Tusquets, pp. 128-135. 
tación peyorativa Sánchez Arteaga, se constituye en factor epistemológico de primer orden ${ }^{3}$. La búsqueda de sostén empírico para tales propuestas acabó por forzar la interpretación de diversos tipos de «evidencias» (desde paleontológicas y arqueológicas, hasta filológicas) para hacerlas entrar en la horma de los esquemas evolutivos que trazaban el origen de la humanidad desde el Terciario. Naturalmente, desde el punto de vista de muchos antievolucionistas pero también de evolucionistas menos propensos a la construcción de magnos esquemas a priori-, el hombre terciario se convirtió a su vez en punto focal de impugnaciones y ataques, en muchas ocasiones fáciles de exponer u organizar si atendemos a la debilidad de los argumentos y supuestas pruebas que los partidarios de aquél ponían en liza. Sin embargo, esto no impidió que la idea del hombre terciario adquiriera amplio predicamento durante el último tercio del siglo XIX y que todavía a comienzos del siglo XX siguiera coleando.

GABRIEL DE MORTILLET Y LAS PRIMERAS PROPUESTAS DE LA ANTIGÜEDAD TERCIARIA DE LOS HUMANOS

Uno de los más destacados partidarios tempranos de la extensión hacia el Terciario de los ancestros inmediatos del hombre actual fue el francés Gabriel de Mortillet (1821-1898), autor del célebre sistema para las fases de evolución cultural de la humanidad en el Paleolítico basado en las características típicas de las herramientas de piedra, y cuyos períodos recibían nombres de yacimientos franceses de referencia (Solutrense por la Roche de Solutré, en Maçon, departamento de Saona y Loira; Musteriense, por Le Moustier, Dordoña; Magdaleniense, por la cueva de La Madeleine, en Tursac, también Dordoña, etc.). Esta orientación tipológica superó la insegura cronología de base paleontológica de Édouard Lartet (1801-1871), en la que las fases se caracterizaban por la fauna a la que se asociaban (edad del Oso de las cavernas, edad del Elefante y del Rinoceronte, edad del Reno, edad del Uro, a las que luego añadiría Felix Garrigou una más antigua edad del Hipopótamo) ${ }^{4}$. La clasificación industrial de Mortillet era una extrapolación y aplicación de

3 SÁnchez Arteaga, J.M. (2007), La fantasía como factor epistemológico en la construcción de las primera teorías darwinianas sobre evolución humana (1859-1912), Cronos, 10, pp. 137-175.

4 Moro, O. (2005), Pour une nouvelle histoire des sciences humaines: Lartet, Mortillet, Piette et le temps de la Préhistoire, Bulletin de la Société préhistorique française, 102 (4), pp. 715-720. 
los principios de las ciencias naturales, y en concreto de la paleontología estratigráfica, a la arqueología: allí donde aquélla usaba la sucesión de restos fósiles típicos para caracterizar y situar cronológicamente los terrenos, ésta echaba mano de los restos de industria lítica típicos para un fin similar. Incluso en el modo de dar nombre a cada época, mediante una derivación del nombre de una localidad así mismo típica, se inspiró Mortillet en la estratigrafía 5 . En el fondo, como señala Bowler, Mortillet asumía un desarrollo evolutivo gradual de la humanidad ${ }^{6}$, tanto en lo cultural como en lo biológico. De hecho, desde presupuestos firmemente materialistas - coherentes, por otro lado, con su adhesión al socialismo-, Mortillet consideraba que la evolución cultural de la humanidad era, en definitiva, una simple extensión de la biológica en sus fases finales. Y por ello postuló, a pesar de no contar todavía con restos fósiles que lo corroboraran, que las formas humanas más antiguas debían haberse dado al final del Terciario.

Para ello, Mortillet apeló a los descubrimientos del sacerdote Louis Bourgeois (1819-1878), que en 1867 había hallado entre las localidades francesas de Pointlevoy y Thenay, en el departamento de Loir y Cher, lo que parecía ser una muestra de herramientas de piedra en unos depósitos terciarios. Mortillet, en 1881, llamó «eolitos» a estos ejemplares. La controversia sobre los eolitos recorre varias décadas a lo largo del último tercio del siglo XIX y primero del siglo XX. Los hallazgos de Bourgeois fueron debatidos ya en el Sexto Congreso Internacional de Antropología y Arqueología Prehistóricas, celebrado en Bruselas en 1872. Nuevos yacimientos vinieron a sumarse a aquél, lo cual no hizo sino alimentar aún más el enfrentamiento de Mortillet y los partidarios de la edad terciaria de la humanidad, con los que no admitían una extensión más hacia atrás del Cuaternario ${ }^{7}$. Como no podía ser de otro modo al tratarse de un tema que afectaba a los orígenes de nuestra especie, la cuestión

5 Coye, N. (2005), Remous dans le creuset des temps: la Préhistoire à l'épreuve des traditions académiques (1850-1950), Bulletin de la Société préhistorique française, 102 (4), pp. 701-707.

6 Bowler, P.J. (1986), Theories of Human Evolution. A Century of Debate, 1844-1944, Baltimore, The Johns Hopkins University Press, pp. 26-30. Unas interesantes consideraciones sobre la matriz lamarckista del pensamiento de Mortillet, con referencia a aportaciones de otros autores, en Guillomet-Malmassari, V. (2005), Le développement de la Préhistoire au $19^{\mathrm{e}}$ siècle: un apprivoisement du temps, Bulletin de la Société préhistorique française, 102 (4), pp. 709-714.

7 Bont, R. de (2003), The Creation of Prehistoric Man. Aimé Rutot and the Eolith Controversy, 1900-1920, Isis, 94, pp. 604-630; SOMMER, M. (2004), Eoliths as Evidence for Human Origins? The British Context, History and Philosophy of the Life Sciences, 26, pp. 209-241. 
estrictamente científica - ¿eran los eolitos un producto de la industria humana, o bien meros artefactos naturales?- se mezcló con tomas de postura filosóficas y religiosas, especialmente después de que el mismo Mortillet planteara en 1873, en el congreso de la Asociación Francesa para el Progreso de las Ciencias, la cuestión del precursor del hombre en relación con la industria lítica terciaria. En 1879, en la Revue d'anthropologie que dirigía Paul Broca, sugirió el nombre de Anthropopithecus para designar tal precursor, ser intermedio entre los simios antropoides y el hombre. En 1883, detalló la propuesta en su libro Le Préhistorique, y así postuló la especie A. bourgeoisii para la correspondiente al autor o autores de los instrumentos de Pointlevoy-Thenay. La audacia de Mortillet no quedó aquí, pues nombró una segunda especie, $A$. ramesii, a la que corresponderían los hipotéticos autores de los instrumentos encontrados en 1877 en Puy-Courny, cerca de Aurillac (Cantal, Francia), por J.B. Rames. Basaba esta diferenciación específica en que aquellos restos correspondían al Aquitaniense, en la base del Mioceno, mientras que éstos se databan en el Tortoniense, en la culminación del mismo. Tal diferencia de edad, en la perspectiva evolucionista de Mortillet, sólo podía sustanciarse en especies biológicas distintas, por cuanto consideraba que se había producido un cambio completo de fauna. Aún propuso una tercera especie, A. ribeiroi, correspondiente a la industria lítica de Ota (Portugal, cerca de Lisboa), hallada en 1871, de edad seguramente similar a la de Puy-Courny, pero tan particular en sus rasgos que podía hacer pensar en un autor diferente. Entre $A$. bourgeoisii y $A$. ribeiroi se habría dado un incremento de talla corporal, acercándose ésta gradualmente a la del hombre moderno, inferencia que el autor derivaba del propio aumento de tamaño de las piedras talladas ${ }^{8}$.

Los epítetos específicos empleados por Mortillet para sus especies homenajeaban a los descubridores de los yacimientos líticos. El de Ota ${ }^{9}$, concreta-

8 Mortillet, G. de (1883), Le préhistorique. Antiquité de l'homme, Paris, C. Reinwald, p. 104-106. Una modificación posterior, puramente nomenclatural, de la propuesta taxonómica de Mortillet se produjo cuando la designación genérica Anthropopithecus fue sustituida por él mismo por Homosimius, ya que aquélla había sido establecida con antelación para referirse a un género de simios; v. Mortillet, G. de y Mortillet, A. de (1910), La préhistoire. Origine et antiquité de l'homme, Paris, Librairie Schleicher Frères, p. 97, donde se reconsidera «beaucop moins certain» Homosimius ramesii que las otras dos especies. Hoy en día, Anthropopithecus está relegado como sinónimo de Pan, nombre establecido por Lorenz Oken en 1816. Pan es el género del chimpancé, P. troglodytes, y del bonobo, P. paniscus; v. WiLSON, D.E. y ReEDER, D.M., (eds.) (2005), Mammal Species of the World. A Taxonomic and Geographic Reference, Baltimore, The Johns Hopkins University Press.

9 «Otta» en la ortografía portuguesa del siglo XIX. 
mente, había sido dado a conocer por el portugués Carlos Ribeiro (18131882), director del servicio geológico de Portugal, quien desde los años sesenta había recogido evidencias de industrias líticas en las cuencas de los ríos Tajo y Sado. Ribeiro sostenía que algunos de estos ejemplares debían ser datados como miocenos, y como tales los presentó en el Sexto Congreso Internacional de Antropología y Arqueología Prehistóricas de 1872, al que se le había invitado apresuradamente. Ribeiro, en general, no logró convencer a los especialistas. Mayor éxito, sin embargo, recabó en 1878, al mostrar una colección de cerca de 100 ejemplares en la Exposición Internacional de París. Allí los contempló Gabriel de Mortillet, quien desde entonces incorporó los datos en cuestión a sus propios trabajos. En 1880, el Noveno Congreso se celebró en Lisboa, y para tal ocasión, Ribeiro preparó una comunicación sobre el hombre terciario en Portugal; además, se organizó una excursión a Ota - en la que no participó el propio Ribeiro, por estar enfermo-, donde in situ los especialistas, entre los que se contaba el español Juan Vilanova - que en aquel congreso se destacó como activo detractor de la datación terciaria ${ }^{10}$-, pudieron estudiar muestras e incluso extraer alguna pieza tal vez anterior al cuaternario $^{11}$. A la postre, la comisión creada ex profeso en el seno del Congreso para discutir la intencionalidad de las piezas supuestamente talladas decantó un veredicto contrario, si bien por margen muy estrecho (seis votos contra cinco). El propio presidente de la comisión, Rudolf Virchow, que se oponía a la tesis de los eolitos, propuso ante ello que se aplazara un dictamen definitivo para una reunión posterior del Congreso, toda vez que no parecía muy científico decidir una cuestión así por mera votación. De hecho, en la Décima Sesión, celebrada en París en 1889, ya fallecido Ribeiro, el discípulo y sucesor de éste, Nery Delgado (1835-1908), volvió sobre la cuestión y mostró a los especialistas nuevos ejemplares de eolitos. Algunos de ellos, recogidos en el interior de los estratos, eran claramente distintos de otras muestras, recolectadas en la superficie y de las que era difícil dudar que mostraran trabajo humano. Muchos años después, en 1942, Henri Breuil y George Zbys-

10 Salavert, V.L., Pelayo, F. y Gozalo, R. (2003), Los inicios de la prehistoria en la España del siglo XIX: Juan Vilanova y Piera y el origen y antigüedad del hombre, Valencia, Universitat de València-Fundación Marcelino Botín [CD-ROM], p. 82.

11 CARdoso, J.L. (1999-2000), As investigações de Carlos Ribeiro e de Nery Delgado sobre o 'homem terciário': resultados e consequências na época e para além dela, Estudos Arqueológicos de Oeiras, 8, pp. 33-54; CARNEIRO, A. (2005), Outside government science, «Not a single tiny bone to cheer us up!» The Geological Survey of Portugal (1857-1908), the involvement of common men, and the reaction of civil society to geological research, Annals of Science, 62, pp. 141-204; SÁNCHEZ ARTEAGA (2007), p. 148-150. 
zewski aclararon definitivamente la cuestión: los eolitos que aparecían in situ en los estratos eran efectivamente terciarios, y no habían sido modificados por la acción humana; lo superficiales, por el contrario, con caracteres litológicos diferentes, eran cuaternarios, procedentes de la denudación de la cobertura detrítica, y tenían indudables señales de acción humana ${ }^{12}$.

En retrospectiva, y como señala Sánchez Arteaga, la propuesta de estas «nuevas especies» por parte de Mortillet, construida a partir no de fósiles, sino de restos, por otra parte de interpretación muy dudosa, de industria lítica, vino propiciada «por las proyecciones fantásticas de la imaginación científica sobre tales pedruscos naturales» ${ }^{13}$. Pero no por fantásticas, fueron menos debatidas, entre otras cosas, porque a la fantasía se unía también una manera de interpretar la propia condición humana que entraba en conflicto con una larga tradición de pensamiento religioso y metafísico. Y tal debate, desde luego, también se vivió por tierras española.

\section{EL INTERÉS DE JUAN VILANOVA POR EL HOMBRE TERCIARIO}

Entre los autores españoles, fue precisamente el valenciano Juan Vilanova y Piera (1821-1893), a la sazón catedrático de Geología y Paleontología en la Universidad Central en Madrid y Catedrático de Paleontología desde 1878, ferviente católico y paladín de la armonización de la ciencia y la religión ${ }^{14}$,

12 Cardoso, J.L. (2008), Joaquim Filipe Nery Delgado, arqueólogo. En Ramalho, M. de Magalhães (coord.), Nery Delgado (1835-1908), Geólogo do Reino, Lisboa, Museu Geológico-Instituto Nacional de Engenharia, Tecnologia e Inovação, I.P.-Centro de História e Filosofia da Ciência-FCTUNL, pp. 63-81.

13 SÁnchez Arteaga (2007), p. 151.

14 Glick, T.F. (1982), Darwin en España, Barcelona, Península, pp. 42-43; Gozalo, R. (1993), Biografía de Juan Vilanova y Piera. En Homenaje a Juan Vilanova y Piera. Valencia, 25-27 de noviembre de 1993, Valencia, Departamento de Geología de la Universitat de València-Servicio de Investigación Prehistórica de la Diputación de Valencia-Sociedad Económica de Amigos del País de Valencia, pp. 11-83, pp. 60-64. Otras aproximaciones al conjunto de la vida y obra de Vilanova, en Portela, E. (1983), Vilanova y Piera, Juan. En López Piñero, J.M., Glick, T.F., NaVarro, V. y Portela, E. (dirs.), Diccionario Histórico de la Ciencia Moderna en España, Barcelona, Ediciones 62, vol. 2, pp. 414-416; GozALO, R., Pelayo, F. y Sequeiros, L. (1993), Juan Vilanova y Piera: Centenario de su muerte (18931993), Revista Española de Paleontología, 8, pp. 121-124; Gozalo, R. y SALAVERT, V.L. (1995), Joan Vilanova i Piera (València, 1821-Madrid, 1893). Geòleg, paleontòleg i prehistoriador. En CAMARASA, J.M. y RocA, A. (dirs.), Ciència i Tècnica als Països Catalans: una aproximació biogràfica, Barcelona, Fundació Catalana per a la Recerca, pp. 287-313. Sobre la 
quien más interés puso en la cuestión del hombre terciario desde sus inicios ${ }^{15}$. En una de sus obras principales, Origen, naturaleza y antigüedad del Hombre, publicada en 1872, Vilanova hablaba de los descubrimientos de Bourgeois y de otros hallazgos de presunta industria lítica, de edad miocena. Según las condiciones climáticas que podían reconstruirse a partir de los datos geológicos y paleontológicos del Mioceno, Vilanova afirmaba sin ambages que «no hay razón científica valedera que se oponga á la admisión» de la presencia del hombre en esa época. Ahora bien, Vilanova juzgaba muy dudosas las pruebas presentadas, en cuanto a que había argumentos de peso que hacían pensar que no se trataba de industria, sino de formas no sometidas a modificación por los seres humanos. Mucho más receptivo era, por el contrario, a ciertas evidencias que apuntaban a una antigüedad menor, pero aun así correspondiente al Terciario, hasta el punto de aseverar que «la existencia del hombre y de los restos de su industria en el terreno terciario superior, parece hallarse fuera de toda duda». Estimaba como pruebas principales algunos restos de útiles de piedra y, sobre todo, de huesos de animales que habrían estado sometidos a la acción humana, que correspondían al Plioceno y que habían sido encontrados en Francia, Italia y Suiza. A esto añadía el siempre bien informado Vilanova, aunque más reservadamente, el hallazgo en California de un cráneo humano en estratos de esa edad ${ }^{16}$. Se trataba del luego célebre «cráneo de Calaveras», llamado así por el condado californiano de ese

actitud de Vilanova ante el evolucionismo, además de los anteriores, v. SEQUEIROS, L. (1984), Impacto del darwinismo en la paleontología española: Juan Vilanova y Piera (1821-1893). En Hormigón, M. (ed.), Actas del II Congreso de la Sociedad Española de Historia de las Ciencias, Zaragoza, Sociedad Española de Historia de las Ciencias, vol. 1, pp. 523-538; Pelayo, F. (1984), La paleontología. Un argumento para rebatir al darwinismo en el intento de armonizar ciencias naturales y religión. En Hormigón, M. (ed.), Actas del II Congreso de la Sociedad Española de Historia de las Ciencias, Zaragoza, Sociedad Española de Historia de las Ciencias, vol. 1, pp. 475-488, y especialmente PELAYo (1999), pp. 113-134 y pp. 183-221, además de Salavert, Pelayo y Gozalo (2003), passim.

15 Esto, por mucho que enfáticamente dijera con ocasión del Congreso Católico Nacional de 1889, y ante un público entre el que había no pocos obispos, que a él la posibilidad de la existencia del hombre terciario le tenía «absolutamente sin cuidado», si bien aclaraba que era «por cuanto el hecho no acusaría contradicción con lo dicho por el legislador hebreo» (es decir, por Moisés en cuanto autor al que tradicionalmente se atribuía la redacción del libro del Génesis); v. Vilanova, J. (1889a), Discurso pronunciado por el Sr. Dr. D... Catedrático de la Universidad Central en la sesión quinta del Congreso Católico Nacional el día 30 de abril de 1889, Madrid, Tipografía de los Huérfanos, p. 16.

16 Vilanova, J. (1872), Origen, naturaleza y antigüedad del hombre, Madrid, Compañía de Impresores y Libreros del Reino, pp. 159-170. 
nombre donde fue hallado en febrero de 1866, en unas gravas auríferas. El ejemplar llegó a manos de Josiah D. Whitney (1819-1896), director del Servicio Geológico de California, quien pronto difundió el descubrimiento en diversos foros científicos. Whitney defendía la atribución del cráneo al Plioceno, pero pronto encontró la oposición de otros autores, entre ellos el geólogo William Blake (1826-1910), que desde hacía tiempo mantenía una conflictiva relación con aquél, y que sospechaba que el cráneo procedía de un enterramiento indio. A pesar de las pruebas que se acumulaban en su contra, Whitney se mantuvo en su opinión hasta su muerte. Poco después, se demostraría sin duda que el cráneo era reciente ${ }^{17}$. De hecho, parece ser que el cráneo adquirido por Whitney no era el hallado en la mina, y que posiblemente éste había sido colocado deliberadamente por unos trabajadores con ganas de broma, circunstancia a la que se unió el ansia, no exenta de componente ideológico, por probar la existencia de una humanidad antigua en Norteamérica ${ }^{18}$.

En 1875, Vilanova se ocupó de nuevo del hombre terciario en una de las numerosas conferencias sobre paleontología humana y prehistoria que impartió en el Ateneo de Madrid ${ }^{19}$ y que fueron publicadas por la Revista Euro$p_{e} a^{20}$. En ella, atacaba las interpretaciones transformistas que postulaban la existencia de una forma intermedia entre el mono y el hombre - al que identificaba con el hombre-mono mudo o Pithecanthropus alalus, propuesto por Haeckel $^{21}$ — para cubrir el gran espacio temporal que se abría entre el Mioce-

17 Testa, S.M. (2002), Josiah D. Whitney and William P. Blake: Conflicts in relation to California geology and the fate of the first California geological survey, Earth Sciences History, 21 (1), pp. 46-76.

18 DeXTER, R.W. (1986), Historical Aspects of the Calaveras Skull Controversy, American Antiquity, 51, pp. 365-369.

19 Sala Catalá, J. (1987), Ideología y Ciencia Biológica en España entre 1860 y 1881. La difusión de un paradigma, Madrid, CSIC, p. 98; Gozalo (1993), p. 69; SALAVERT, Pelayo y Gozalo (2003), p. 44.

20 La Revista Europea, publicada entre 1874 y 1880, era una publicación dedicada a la modernización de la cultura española. Fue vehículo de expresión habitual de autores evolucionistas relacionados con el positivismo y el krausismo. No obstante, su pluralidad llevó a admitir también trabajos como los de Vilanova, que mostraban posturas ideológicas y científicas bastante alejadas de aquéllas; v. SALA (1987).

21 Una interesante reflexión sobre esta propuesta haeckeliana, en relación con las polémicas sobre el origen geográfico de la humanidad, en SÁnChEZ ArTEAGA (2007). La idea de Haeckel de una evolución desde el mudo P. alalus al hablador Protanthropus primigenius la hipotética primera forma verdaderamente humana - implicaba toda una filogenia del alma (Seele) humana, concebida básicamente como conjunto de poderes mentales; v. Di GrEGORIO, M.A. (2005), From Here to Eternity. Ernst Haeckel and Scientific Faith, Göttingen, 
no y la época actual, y consideraba que «a estas extravagancias científicas [...] conduce, primero, el no querer admitir en la creación del hombre la acción todopoderosa de un Dios personal, y segundo, la obediencia ciega á una teoría fundada también en hipótesis» ${ }^{22}$. Al mismo tiempo, Vilanova se mostraba muy crítico con aquellos que no admitían todavía la existencia de restos fósiles genuinamente humanos ni siquiera en la formación diluvial cuaternaria, y que por ello acababan por postular una especie diferente a la humana, similar orgánicamente a la nuestra pero, en definitiva, carente de las virtudes del libre albedrío y la moralidad. Se daba así, en su opinión, una sorprendente convergencia entre las posturas de los transformistas y las de «los más intransigentes detractores de la ciencia prehistórica», al postular en ambos casos, a partir de asunciones completamente distintas - evolucionista en un caso, fijistacreacionista en el otro-, la existencia de una forma intermedia entre mono y hombre ${ }^{23}$. Vilanova señalaba que «del Mioceno sólo conocemos, y he visto, instrumentos de pedernal» ${ }^{24}$, sobre los cuales, los principales especialistas europeos no se ponían de acuerdo — admisión que minaba la rotundidad con que se expresaba en 1872 - en cuanto a si eran productos de la acción humana. Aun así, si se demostrara que lo eran, o incluso si se hallaran fósiles humanos terciarios - no se tenía en consideración, en esta ocasión, el cráneo de Calaveras-, Vilanova no encontraba problema en admitir que, efectivamente, nuestra especie era más antigua de lo que se pensaba. ¿Cómo habría entonces sobrevivido a tantos cambios faunísticos $-\mathrm{y}$ por ende, ambientales - desde tan remota época? Sin duda, por la superioridad del hombre desde su creación respecto a los animales, manifestada en la inteligencia. Respecto a su libro de 1872, el tono del discurso de Vilanova, en definitiva, se había vuelto menos contemporizador y más crítico tanto en la valoración de las pruebas como, sobre todo, en la exposición de las explicaciones evolucionistas. De hecho, como se ha señalado en otros estudios ${ }^{25}$, Vilanova alcanzó un punto de máximo rechazo del darwinismo - al menos, en el modo de expre-

\footnotetext{
Vandenhoeck \& Ruprecht, p. 479. No extraña, pues, el rechazo que a ello manifestaran tantos autores católicos. La influencia de Haeckel en los estudios de evolución lingüística puede verse en Richards, R. (2008), The Tragic Sense of Life. Ernst Haeckel and the Struggle over Evolutionary Thought, Chicago, The University of Chicago Press, pp. 255 ss.

22 Vilanova, J. (1875), Ciencia prehistórica. V. El hombre terciario, Revista Europea, 6, pp. 277-280, p. 277.

23 Vilanova fue especialmente beligerante con la interpretación preadamita del apologista Francisco Caminero; v. PELAYO (1999), pp. 216. y p. 265-267.

24 Vilanova (1875), p. 279.

25 Sequeiros (1984); v. también Salavert, Pelayo y Gozalo (2003), passim.
} 
sarse - en, precisamente, la siguiente de sus conferencias sobre ciencia prehistórica en el Ateneo, donde apelaba a la inexistencia de formas fósiles intermedias como principal argumento contra la doctrina de Darwin, y en la que denunciaba incluso la extensión de ésta a ámbitos ajenos a la historia natural, como el derecho ${ }^{26}$.

El rechazo de Vilanova a la validez de las pruebas aportadas en pro de la existencia del hombre terciario - aunque no a la posibilidad de la existencia de éste, según los datos paleoclimáticos- se confirmó en el discurso que pronunció en abril de 1889 en el Congreso Católico Nacional. El grueso de la intervención de Vilanova estuvo dedicado a describir los principales rasgos geológicos, paleontológicos y climáticos de las grandes eras de la historia terrestre, asumiendo que la ciencia no permitía todavía ofrecer dataciones de tiempo absolutas, pero no adoptando en ningún caso cómputos supuestamente basados en las Sagradas Escrituras. El concordismo de Vilanova, pues, era firme, pero no al precio de transigir con las interpretaciones restrictivas de muchos exégetas ni con el literalismo bíblico. Así,

podemos afirmar, vista la lentitud suma con que se forman hoy los depósitos que constituyen el principal y más importante yacimiento de los restos del hombre y de su primitiva industria, el del acarreo antiguo ó Diluvium, que excede bastante aquel tiempo del señalado en los varios cómputos que sin carácter dogmático se han hecho por cronistas é historiadores insignes. No citando fechas absolutas el Génesis mosaico, y estando sujeta á controversias la cronología sagrada, claro está que por mucha que sea la antigüedad que los hechos, no las teorías pre, y mejor protohistóricas, concedan al hombre en la tierra, en manera alguna puede contrariar á la que sirve de sólido fundamento á nuestras arraigadas creencias, llegando en esta materia hasta asegurar que poca alarma debe producir la posibilidad de la existencia del hombre ó de su inmediato ascendiente el antropopíteco, según pretenden los transformistas, en el terreno terciario, siquiera el hecho diste aún mucho de haberse realizado, como intenté demostrar en el cuerpo del discurso ${ }^{27}$.

¿Cómo planteó tal demostración? Tras hacer memoria brevemente de los descubrimientos de presunta industria lítica terciaria por Bourgeois — cuya condición de sacerdote católico recuerda y cuya ortodoxia reivindica-, Rames y Ribeiro, señalaba que los estudios de Cotteau en el yacimiento de Thenay habían indicado la insignificancia de los objetos allí encontrados y de las

26 Vilanova, J. (1876), Ciencia prehistórica. VI y VII. La doctrina de Darwin, Revista Europea, 7, pp. 356-358.

27 Vilanova (1889a), p. 23. 
múltiples posibilidades de interpretación que mostraban. En cuanto a los restos de Auvernia y Portugal, era clave el hecho de que se encontraban sobre la superficie del terreno y no incluidos en él, lo que impedía afirmar que pertenecieran realmente al Mioceno. Los datos acerca de incisiones intencionadas aparecidas en restos fósiles de otras especies tampoco merecían ya, según Vilanova, ningún crédito, después de que algunos de sus mismos proponentes se retractaran y, en otros casos, fueran desautorizados por estudios posteriores, como en el caso de las incisiones en huesos de ballenas fósiles que había aportado Giovanni Capellini, y que Stefanis había demostrado que no eran obra de mano humana. En cualquier caso, el ataque más fuerte lo dirigió, como era de esperar, a los que proponían la existencia del hombre terciario en clave transformista. Según Vilanova, «ya no debe [...] llamarse ésta la tesis del hombre terciario, supuesto que los más decididos partidarios la han relegado al olvido, sino del antropopíteco terciario, sér fantástico del cual tampoco vió jamás el menor vestigio su ingenioso fundador», que no era otro que Gabriel de Mortillet, cuya propuesta de las tres especies consideraba «fantasía que cuadra bien poco por cierto con la severidad que exigen los estudios serios de Historia Natural». A la postre, imputaba a los propios evolucionistas, «partidarios del sér intermedio, obedeciendo ciegos á las exigencias del sistema», la negación de la existencia de restos fósiles humanos de edad terciaria ${ }^{28}$, aunque él, por supuesto, se sintiera perfectamente a gusto con tal negación.

El 29 de junio de aquel mismo año de 1889, Vilanova ingresó en la Real Academia de la Historia. Era el primer autor procedente del mundo de las ciencias naturales que entraba en dicha institución, en gran medida por la voluntad de su presidente, Antonio Cánovas del Castillo, que incorporaba de ese modo al catedrático de Paleontología al proyecto de una historia general de España destinada a fundamentar una visión nacionalista del país. Vilanova se tendría que hacer cargo, naturalmente, de la prehistoria (o, como el prefería llamarla, protohistoria). Su discurso de ingreso, en buena medida, trataba sintéticamente sobre las líneas fundamentales que Vilanova defendía en la caracterización de tal período ${ }^{29}$. Lógicamente, la cuestión del hombre terciario también fue abordada, con bastante detalle, en esta nueva aportación, que en cualquier caso utilizaba un corpus argumentativo similar al del discurso ante el Congreso Católico Nacional. Y del mismo modo que rechazaba la existencia de restos paleontológicos o arqueológicos que atestiguaran la presencia del hombre o de algún hipotético antecesor en el Terciario, proclamaba

28 Vilanova (1889a), p. 18.

29 Salavert, Pelayo y Gozalo (2003), p. 6. 
que el inicio de la historia de nuestra especie era un «acontecimiento que, con muy contadas excepciones, colocan antropologistas y geólogos, de común acuerdo, en el período cuaternario» ${ }^{30}$. Unas cuantas semanas después del ingreso de Vilanova en la Academia, sin embargo, llegaría a su propia tierra natal un ejemplar humano fósil del que algunos autores sospechaban una inusitada antigüedad. El «hombre terciario» aún iba a darle bastante de que hablar.

\section{UN ESQUELETO HUMANO FÓSIL EN VALENCIA}

En agosto de 1889 llegó a Valencia una magnífica colección de mamíferos fósiles procedentes de Argentina ${ }^{31}$ (figura 1), que había sido adquirida por José Rodrigo Botet (1842-1915). Rodrigo, que era natural de Manises (Valencia), se estableció en el país suramericano en 1875. Allí dirigió diversas obras de ingeniería civil que le permitieron acumular una gran fortuna, parte de la cual invirtió en la compra de restos fósiles. Al respecto, fue fundamental su relación con otro español que trabajaba en Argentina, el catalán Enrique de Carles $^{32}$, que prestaba servicios como naturalista recolector para el Museo de Buenos Aires y que fue quien vendió los ejemplares a Rodrigo. Éste decidió

30 Vilanova, J. (1889b), Discurso del Dr. D... En Discursos leidos en la Real Academia de la Historia en la recepción públicas del Dr. D. Juan Vilanova y Piera el día 29 de junio de 1889, Madrid, A. Pérez Dubrull, pp. 1-92, p. 26. En el discurso de contestación, Cánovas remachaba el punto de vista de Vilanova al señalar que «no hay para qué ocuparse, hoy por hoy, en conciliar con la verdad revelada al supuesto hombre terciario»; v. CÁNOVAS DEL Castillo, A. (1889), Contestación del Excmo. Sr. D... En Discursos leídos en la Real Academia de la Historia en la recepción públicas del Dr. D. Juan Vilanova y Piera el día 29 de junio de 1889, Madrid, A. Pérez Dubrull, pp. 93-136, p. 108.

31 Sobre el flujo de fósiles de mamíferos desde Argentina a Europa (especialmente a Francia e Inglaterra), v. PodGORNY, I. (2000), Los gliptodontes en París: las colecciones de mamíferos fósiles pampeanos en los museos europeos del siglo XIX. En MonTSERRAT, M. (comp.), La ciencia en la Argentina entre siglos. Textos, contextos e instituciones, Buenos Aires, Manantial, pp. 309-327, así como PoDGORNY, I. (2001a), El camino de los fósiles: las colecciones de mamíferos pampeanos en los museos franceses e ingleses del siglo XIX, Asclepio, 53 (2), pp. 97-115.

32 Son escasas las noticias sobre la vida y carrera de Enrique de Carles, aunque se sabe que llegó a Argentina por los años setenta del siglo XIX y todavía trabajaba allí en la segunda década del siglo XX; algunos datos interesantes sobre este personaje en SALINAS, M.A. (2001), Las colecciones paleontológica y conquiológica del Museo Paleontológico J. Rodrigo Botet de Valencia: inventario faunistico, importancia científica, museística e histórica, Valencia, Universitat de València [tesis doctoral inédita]. 


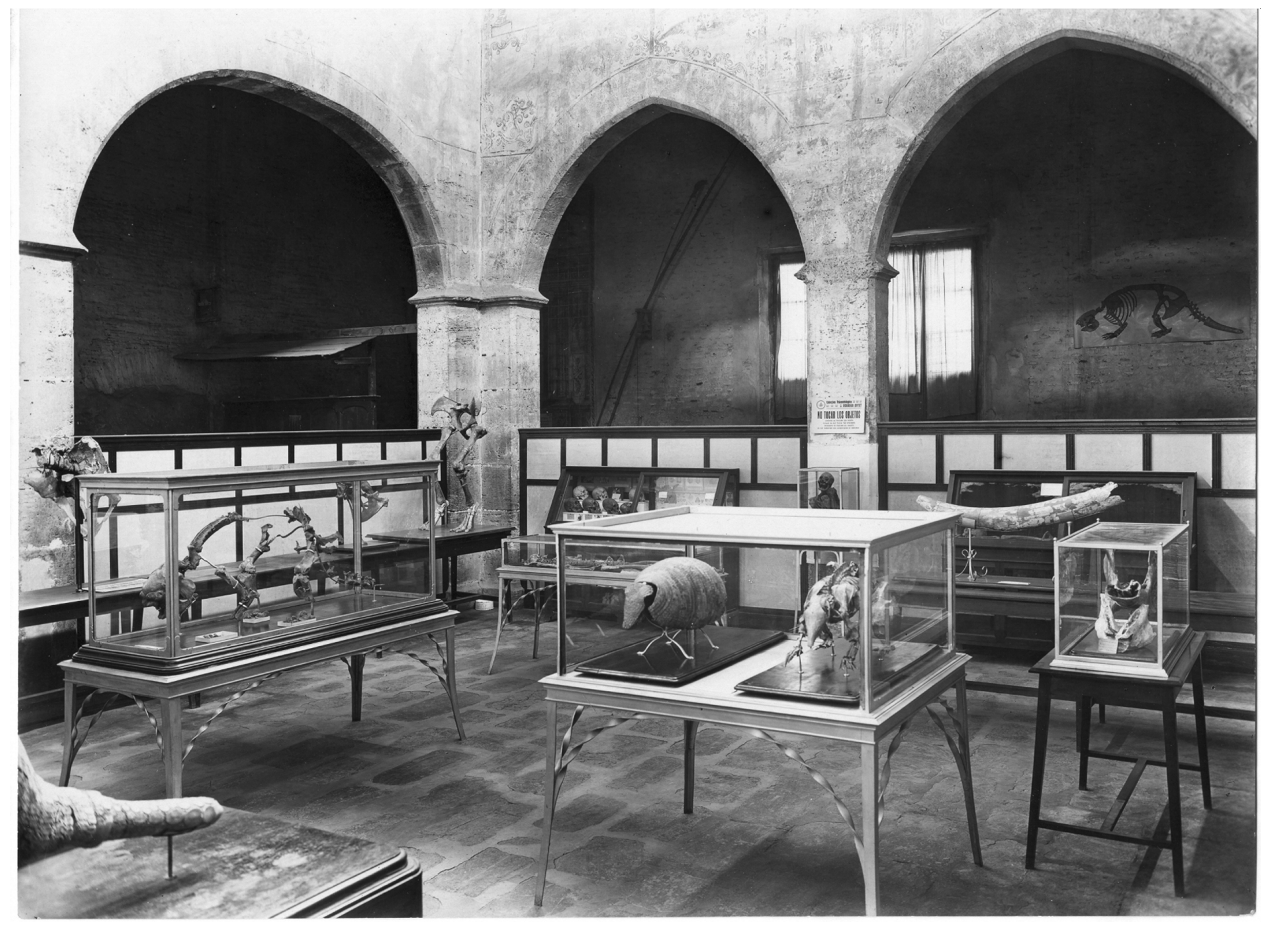

Figura 1. Vista parcial de la colección paleontológica donada por José Rodrigo Botet, en el Almudín de Valencia; en segundo plano, a la derecha del ángulo de la nave, la sección antropológica, con la vitrina que alojaba el esqueleto humano fósil de Samborombón. Autor: Vicente Barberá Masip, ca. 1927. (Fuente: Archivo del Museo de Ciencias Naturales de Valencia).

donarlos a la ciudad de Valencia, que pasaba así a tener una de las más importantes colecciones en su género de todo el mundo. Por aquel entonces, como hoy en día, asombra la espectacularidad de los animales característicos de la fauna del Pleistoceno sudamericano, que en conjunto conforman una de las muestras más grandiosas en toda la historia de la Tierra ${ }^{33}$. Aunque actual-

33 Salinas, M.A. (2000), Un proyecto de instalación del Museo Paleontológico Rodrigo Botet de Valencia en la primera década del siglo XX. En BAtLló, J., Fuente, P. de la y PUIG, R. (coords.), Actes de les V Trobades d'Història de la Ciència $i$ de la Tècnica als Països Catalans, Observatori de l'Ebre, 11-13 de desembre de 1998, Barcelona, Societat Catalana d'Història de la Ciència i de la Tècnica, pp. 485-492. 
mente ya no es una cuestión polémica, la datación de esta fauna sí lo era en aquella época, pues había autores que la referían al Plioceno (es decir, todavía en el Terciario), frente a otros que efectivamente la situaban - como ahora pensamos - en el Pleistoceno (o sea, dentro del Cuaternario). La polémica se enconaba aún más por el hecho de haberse hallado diversos e importantes restos fósiles humanos en tales depósitos, conocidos como «terrenos pampeanos» desde su descripción por Alcide d'Orbigny en 1842, o como «formación pampeana» a partir de la propuesta de Charles Darwin de $1845^{34}$.

Las primeras noticias contrastadas sobre el valor científico de la colección de Valencia las ofreció Vilanova, que tuvo la oportunidad de recabar información de primera mano sobre la misma al efectuar una visita a comienzos de 1890, guiado por el propio Enrique de Carles. Vilanova dio cuenta de sus impresiones en un artículo en el diario local Las Provincias, aparecido en sendas entregas los días 5 y 8 de enero ${ }^{35}$. Los trabajos de montaje de los ejemplares, desde luego, apenas se habían iniciado, aunque el autor ya procuraba inculcar a los lectores la idea de que Valencia, ciertamente, había sido agraciada con una colección de grandísimo interés científico.

Vilanova, en la primera entrega, expuso con bastante detalle diversos argumentos sobre la edad cuaternaria de los restos. Para ello, evocó un trabajo de de Carles relativo a sus excavaciones en el valle de Tarija (Bolivia) ${ }^{36}$, a propósito de la característica presentación dispersa de los restos fósiles de vertebrados en las formaciones diluviales cuaternarias, así en América como en Europa. También hizo valer su propia experiencia como paleontólogo, al hacer notar que el examen que, durante la visita, efectuó de la roca donde se hallaron los fósiles no le ofrecía duda alguna de que correspondía al «cieno diluvial europeo» ${ }^{37}$. Todo ello, reconocía, para esclarecer el «importante

34 Tonni, E.P. y Pasquali, R.C. (2006), Alcide d'Orbigny in Argentina: The beginning of stratigraphical studies and theories on the origin of the "Pampean sediments», Earth Sciences History, 25, pp. 215-223.

35 Vilanova, J. (1890a), Colección paleontológica que Valencia debe al celo é inteligencia de señor Carles, y á la patriótica generosidad del Sr. Botet, Las Provincias, 5 y 8 de enero de 1890.

36 CARLES, E. de (1888), Noticias sobre un viaje á Tarija (Bolivia), Boletín del Instituto Geográfico Argentino, 9 (2), pp. 35-40.

37 El uso de las analogías en el aspecto de las rocas para establecer correlaciones entre Europa y Sudamérica se criticaba ya en la época por diversos autores que desarrollaban su labor al otro lado del Atlántico; v. Podgorny, I. (2005), Bones and Devices in the Constitution of Paleontology in Argentina at the End of the Nineteenth Century, Science in Context, 18 (2), pp. 249-283. 
asunto del yacimiento de todas aquellas riquezas paleontológicas, que no es terciario, como han pretendido algunos, y entre ellos mi amigo Sr. Ameghino, de Buenos Aires». Y añadía a continuación:

\footnotetext{
Y no se crea que el asunto es baladí o de escasa significación, pues se relaciona con la posible existencia del hombre terciario, lo propio en América que en el viejo Continente. Y como quiera que entre los tesoros traídos, y que vimos ayer, figuran casi todos los huesos de un esqueleto humano, notables, por cierto, bajo muchos conceptos, según tendré ocasión de probar más adelante, creo que los discretos lectores no tomarán a mal que les diga algo sobre tan grave asunto ${ }^{38}$.
}

Vilanova, entonces, daba cuenta somera, una vez más, de la polémica que animaba el postulado de que la especie humana había iniciado su presencia sobre la Tierra en el Terciario. Recordaba como uno de los principales defensores de tal idea al mencionado Florentino Ameghino (1854-1911), a quien efectivamente conocía personalmente tras coincidir en la Exposición de París y en el primer Congreso Geológico Internacional. Ameghino, hijo de emigrantes italianos, era un autodidacta de la paleontología, la arqueología y la antropología. En 1878 viajó a París, ciudad en la que permaneció hasta 1881, trabajando en el Muséum d'Histoire Naturelle con Henri Gervais, vendiendo ejemplares de fósiles de mamíferos argentinos a diversos coleccionistas y adquiriendo un nombre entre los especialistas del momento. Allí también se casó. Ya de vuelta a Argentina, ocupó brevemente un puesto universitario en Córdoba, de donde pasó como subdirector al Museo de la Plata. Aquí se enfrentó con Francisco Moreno, director del establecimiento, lo que conllevó la dimisión de Ameghino en 1887. Abrió entonces una librería que, en realidad, fue hasta comienzos del siglo XX el centro de operaciones de su labor científica, en la que halló una colaboración fundamental por parte de su familia. Así, su hermano Carlos fue el recolector efectivo de casi todos los materiales que estudiara, mientras que otro hermano, Juan, implicado también en ocasiones en trabajos de recolección, le ayudaba sobre todo en el negocio de los libros. Su esposa, finalmente, participaba en todas las tareas y, además, en la corrección de los manuscritos que Ameghino publicaba en francés y en la recepción de los visitantes que llegaban a La Plata a entrevistarse con su marido. La suerte de Ameghino, que a pesar de las dificultades - malos negocios editoriales, depresiones económicas, alejamiento de los centros de investigación - alcanzó por aquellos años un nivel importante de producción científica, cambió en 1902 cuando el ministro de Educación lo nombró director

38 Vilanova (1890a). 
del Museo de Ciencias Naturales de Buenos Aires, cargo en el que permaneció hasta su muerte ${ }^{39}$. Ameghino, que gustaba de considerarse a sí mismo «apóstol» de las ideas evolucionistas, asumió la evolución desde una perspectiva en la que, si atendemos a Orione ${ }^{40}$, predominaban los componentes lamarckistas frente a los darwinistas; algo, por otra parte, muy en consonancia con las tendencias direccionales y adaptacionistas del credo evolutivo de buena parte de los paleontólogos de su época, poco proclives, coherentemente, a esquemas ligados a la selección natural ${ }^{41}$.

A pesar de las graves discrepancias científicas que los separaban, Vilanova se refería a Ameghino de forma cordial, como puede comprobarse no sólo en el artículo de Las Provincias, sino también en el texto del discurso que pronunció en el Ateneo de Madrid en 1891 sobre protohistoria americana, dentro de un ciclo de conferencias americanistas con motivo del cuarto centenario del descubrimiento del Nuevo Mundo. En ese lugar, donde de nuevo repasaba los argumentos en contra del origen terciario del hombre, decía efectivamente:

Más importantes son los datos que Ameghino expone en una obra por muchos conceptos famosa, fruto de sus diligentes pesquisas, muchos de cuyos materiales tuve el gusto de ver en la exposición de París en 1878, donde entablé relaciones de amistad con el celoso é inteligente naturalista buonarense ${ }^{42}$.

La noticia, propiamente, sobre los restos fósiles la reservó Vilanova para la segunda entrega de su artículo en Las Provincias. Significativamente, empe-

39 Gárate, J. (1970), Ameghino, Florentino. En Gillispie, C.C. (ed.), Dictionary of Scientific Biography, New York, Charles Scribner's Sons, vol. 1, pp. 129-132; también, PODGORNY (2005).

40 Orione, J. (1987), Florentino Ameghino y la influencia de Lamarck en la paleontología argentina del siglo XIX, Quipu, 4 (3), pp. 447-471.

41 Sobre el evolucionismo en Argentina en una perspectiva general, especialmente desde el punto de vista ideológico, son útiles MONTSERRAT, M. (1999), La mentalidad evolucionista en la Argentina: una ideología del progreso. En Puig-SAMPER, M.A., Ruiz, R. y GALERA, A. (ed.), Evolucionismo y cultura. Darwinismo en Europa e Iberoamérica, Madrid, Junta de ExtremaduraUniversidad Nacional Autónoma de México-Doce Calles, pp. 19-46, y MONTSERRAT, M. (2000), La sensibilidad evolucionista en la Argentina decimonónica. En MONTSERRAT, M. (comp.), La ciencia en la Argentina entre siglos. Textos, contextos e instituciones, Buenos Aires, Manantial, pp. 203-221. Para el contexto de recepción del darwinismo, v. ORTIZ, E.L. (1984), La polémica del darwinismo y la inserción de la ciencia en Argentina. En Hormigón, M. (ed.), Actas del II Congreso de la Sociedad Española de Historia de las Ciencias, Zaragoza, Sociedad Española de Historia de las Ciencias, vol. 1, pp. 89-108.

42 Vilanova, J. (1892a), Protohistoria americana, Madrid, Sucesores de Rivadeneyra, p. 33. 
zaba con la referencia a un esqueleto humano, hallado en la orilla derecha del río Samborombón, en la provincia de Buenos Aires ${ }^{43}$. El ejemplar, muy completo (figura 2), presentaba algunos rasgos muy peculiares. Vilanova pudo observar in situ el llamativo gran tamaño de la mandíbula inferior, con una rama horizontal muy ancha. Los dientes mostraban un profundo desgaste, con marcas que Vilanova asociaba típicamente a un régimen granívoro: unas señales bastante habituales en muchos restos antiguos, pero que Vilanova reconocía no haber contemplado tan acentuadas como en este caso. Notaba también una infrecuente caries profunda en el tercer molar de cada rama mandibular. Sin poderlo comprobar personalmente, se hacía eco de lo que de Carles le había comentado acerca de otro conjunto de rasgos peculiares del esqueleto: existencia de trece vértebras dorsales, en lugar de doce; situación algo posterior respecto de lo ordinario del agujero occipital de la base del cráneo, lo que llevaría a «una cierta oblicuidad, en vez de mantenerse del todo vertical, como sucede, sobre todo, en las razas civilizadas»; finalmente, la presencia de un orificio en el esternón. Vilanova, sin ambages, admitía que tales rasgos

acusan un cierto grado de inferioridad orgánica, que, a la par que aquilatan el mérito del esqueleto en cuestión, diríase que acreditan su remota antigüedad, la cual se revela también por el estado de su fosilización y por el matiz de los huesos,

43 Este ejemplar iba con el número 2 en la lista-catálogo que Enrique de Carles preparó antes del embarque de la colección. De él se dice en tal documento: «Hombre fósil (Inédito) Río Samborombón (esqueleto armable) Cráneo (faltándole la región frontal, un lado de la parietal, y respectiva cigomática), cúbitos y radios, ilíacos, sacro y coxis, las dos manos, fé$\underline{\text { mures, }}$ tibias y peronés, parte de un pie, rótulas y clavículas. Este esqueleto único tan completo de América está [ilegible por mancha de tinta] sin describirlo por los Doctores Burmeister y Ameghino». Al margen, había dos notas añadidas. Una nota dice «Visto y publicado» (quizá el subrayado haciendo referencia a las partes subrayadas de la descripción). La otra comenta: «Cerrado y la llave existe en poder del vice-cónsul de Buenos Ayres en Játiva. [Roto] el baúl el entresuelo». V. CARLES, E. de, Catálogo de la Colección paleontológica que el ingeniero Don José Rodrigo Botet regala a la ciudad de Valencia, obtenida en las exploraciones efectuadas en la provincia de Buenos Aires (República Argentina) por el naturalista Enrique de Carles [copia manuscrita], Buenos Aires, 1 de enero de 1889, Archivo del Museo de Ciencias Naturales de Valencia (AMCNV), serie Relaciones y listas de piezas del legado de Jose Rodrigo Botet, sobre A, fol. [1]. Una amplia discusión técnica sobre el esqueleto y su inserción en la colección, en Salinas (2001), pp. 231-245. Según estudios recientes, la antigüedad del ejemplar sería de unos 8.000 años; v. Belinchón, M., PeÑAlver, E., MONTOYA, P. y GASCó, F. (2009), Crónicas de fósiles. Las colecciones paleontológicas del Museo de Ciencias Naturales de Valencia, Valencia, Ajuntament de València, p. 121. 
igual en un todo al que ofrecen los demás restos fósiles de la colección, y al color del cieno diluvial, donde unos y otros se han encontrado ${ }^{44}$.

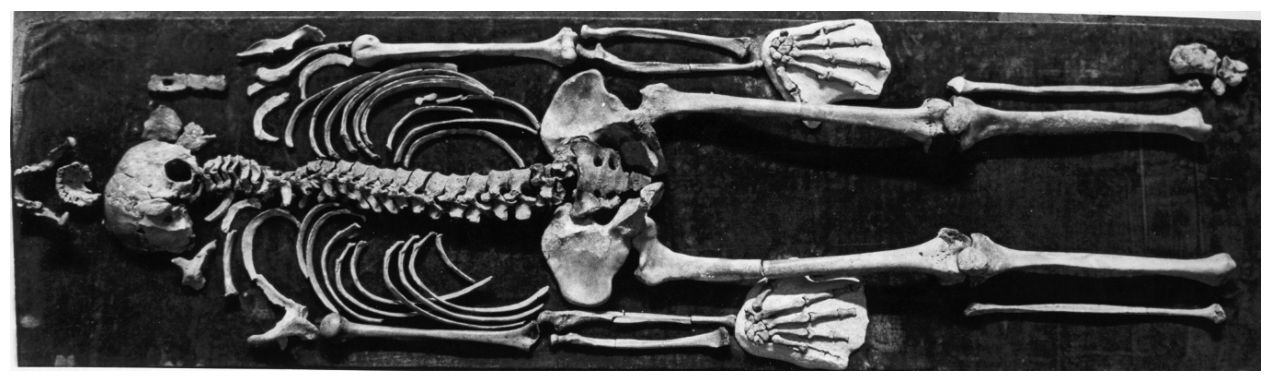

Figura 2. Vista cenital del esqueleto humano fósil de Samborombón, tal como se exponía en el Museo Paleontológico Municipal de Valencia en su ubicación en el Almudín. Autor: Cabrelles Sigüenza, s.a. (Fuente: Archivo del Museo de Ciencias Naturales de Valencia).

Ese «mérito» del esqueleto, desde luego, no había pasado desapercibido para quienes lo vieron antes que Vilanova. Antes de su llegada a Valencia, de hecho, el esqueleto ya había llamado la atención de algunos paleontólogos que trabajaban en Argentina. Seguramente, la primera referencia al ejemplar es obra de Hermann Burmeister (1807-1892), el gran naturalista alemán naturalizado argentino y todopoderoso director del Museo de Buenos Aires ${ }^{45}$, quien publicó en 1884 una breve nota sobre la formación pampeana en los Verhandlungen de la Sociedad Berlinesa de Antropología, Etnología y Prehistoria, bajo la dirección de Rudolf Virchow. La nota venía motivada por otra del año anterior, escrita por el propio Virchow, en la que se daba noticia del hallazgo de restos de Glyptodon y de un ejemplar humano al norte de la provincia de Buenos Aires. Virchow afirmaba en ese trabajo que Burmeister juzgaba la formación geológica en cuestión como marina, a lo que se oponía

44 Vilanova (1890a).

45 La bibliografía sobre Burmeister es amplia. Son estudios muy apreciables AsúA, M. de (1989), El apoyo oficial a la «Description Physique de la République Argentine» de H. Burmeister, Quipu, 6 (3), pp. 339-353; NAVARro, P. y McCASKILl, A. (2001), La «Pampa fértil» y la Patagonia en las primeras geografías argentinas (1876), Biblio 3W. Revista Bibliográfica de Geografia y Ciencias Sociales, 6 (319) disponible en http://www.ub.es/geocrit/b3w-319.htm (consultado el 27-07-2011), que dan a su vez abundantes referencias de otros trabajos. 
Santiago Roth, descubridor de los restos ${ }^{46}$. Burmeister escribió precisamente para aclarar este último punto, pues él no defendía la opinión que se le reputaba por parte de Virchow. Al final de la nota, marginalmente, informaba del hallazgo en la formación pampeana de un segundo esqueleto humano fósil por Enrique de $\mathrm{Carles}^{47}$. Ni Burmeister ni Virchow tenían dudas sobre la edad cuaternaria de la formación pampeana ni de los restos humanos fósiles que contenía. De pensamiento bien diferente era Ameghino, cuyo enfrentamiento con Burmeister a propósito del evolucionismo es conocido ${ }^{48}$. En su Contribución al conocimiento de los mamíferos fósiles de la República Argentina, Ameghino daba más detalles sobre el hallazgo realizado por Enrique de Carles. Lo localizaba en el río o arroyo de Samborombón, muy cerca de su confluencia con el arroyo Dulce. El esqueleto estaba «casi completo, con excepción del cráneo del que solo queda la base, parte de la región posterior y la mandíbula inferior» ${ }^{49}$. Los huesos se encontraron en su disposición relativa original, aunque por un lado iban tronco, extremidades superiores y restos craneales, y por el otro, cadera, sacro y miembros inferiores. Ambos conjuntos estaban a un metro aproximadamente el uno del otro. Las aguas habían puesto a descubierto el cráneo, única parte visible antes de la excavación, lo que explicaba su carácter incompleto. A diferencia de lo que sostendría Vilanova en el artículo de Las Provincias, Ameghino asignaba carácter lacustre y no fluvial al depósito de edad pampeana superior donde se hallaron los restos. Según aseveraba en otro lugar de la misma monografía ${ }^{50}$, el esqueleto humano lo halló de Carles en 1882, enterrado «bastante más abajo» que los restos de Scelidotherium y otros animales que aparecieron en aquel yacimiento. Y señalaba que «esta pieza, notabilísima bajo muchos aspectos, permanece aún

46 VIRCHOW, R. (1883), Ein mit Glyptodon-Resten gefundenes menschliches Skelet aus der Pampa de la Plata, Verhandlungen der Berliner Gesellschaft für Anthropologie, Ethnologie und Urgeschichte, 15, pp. 465-467.

47 «Ein zweites fossiles menschliches Skelet ist hier von Hrn. de Carles gefunden». Burmeister, H. (1884), Pampas-Formation, Verhandlungen der Berliner Gesellschaft für Anthropologie, Ethnologie und Urgeschichte, 16, pp. 246-247, p. 247.

48 Tognetti, L.A. (2001), El apoyo de la Academia Nacional de Ciencias a la publicación de la obra Contribución al conocimiento de los mamíferos fósiles de la República Argentina de Florentino Ameghino, Saber y Tiempo, 11, pp. 33-49. Sobre el antievolucionismo de Burmeister y su escasa sintonía con los científicos argentinos jóvenes, puede consultarse ORTIZ (1984) y MONTSERRAT (2000).

49 Ameghino, F. (1889), Contribución al conocimiento de los mamíferos fósiles de la República Argentina, Buenos Aires, Pablo E. Coni é Hijos, p. 66.

50 Ameghino (1889), p. 47. 
inédita». Ameghino, que admitía haber visto el esqueleto «de paso», destacaba la talla pequeña del individuo (del que se inclinaba a pensar que era de sexo femenino), la posesión de una mandíbula inferior fuerte y maciza, «evidentemente de un cráneo braquicéfalo», la perforación del esternón y la presencia de dieciocho vértebras «dorso-lumbares, anomalía que se presenta rarísimamente en las razas actuales, pero que debe haber sido más frecuente en las razas antiguas, y sin duda un carácter constante de uno de los antecesores del hombre» ${ }^{51}$. Lo atribuía, junto a otros ejemplares, al Plioceno superior, es decir, de edad terciaria tardía.

Ameghino, pues, no llegó a describir formalmente el esqueleto humano de Samborombón, aunque lanzó ya hipótesis, como vemos, bastante atrevidas. El artículo de Vilanova en Las Provincias, en consecuencia, sería la primera respuesta, siquiera informal, a tales especulaciones en lo relativo específicamente al ejemplar. Pero había que dar conocimiento del ejemplar por vías más típicas de la comunicación científica. Con un contenido muy similar, aunque obviando la larga disquisición sobre la polémica del hombre terciario, e introduciendo en su lugar una síntesis del trabajo de Enrique de Carles en Argentina y de la circunstancia en que José Rodrigo Botet sobrepujó la oferta que por la colección reunida por aquél había realizado un museo danés, Vilanova presentó una nota sobre los materiales paleontológicos llegados a Valencia en la sesión científica de 5 de febrero de 1890 de la Sociedad Española de Historia Natural, que fue debidamente publicada en el órgano oficial de ésta $^{52}$. Para completar estas acciones divulgadoras del legado de Rodrigo Botet, Vilanova presentó una breve comunicación ante el Congreso Internacional de Americanistas, celebrado en París en el mes de octubre de aquel mismo año, centrada estrictamente en el esqueleto de Samborombón y en la que, además de describir de nuevo las peculiaridades del ejemplar, interpretaba la oblicuidad de la apófisis mandibular y el consiguiente movimiento de adelante hacia atrás como indicios, junto con el tipo de desgaste de las coronas dentarias, de un régimen frugívoro. Si bien no entraba en disquisiciones sobre su presunta edad terciaria, era categórico en el aspecto estratigráfico al afirmar que el esqueleto había sido hallado «dans la formation pampéenne qui appartient au diluvium américain dont la roche offre tous les caractères du lehm

51 AMEgHiNO (1889), p. 85.

52 Vilanova, J. (1890b), [Noticia sobre el Museo paleontológico del Sr. Botet, de Valencia. Comunicación verbal], Anales de la Sociedad Española de Historia Natural (Actas), 19, pp. 19-25. 
européen» (es decir, cuaternario) ${ }^{53}$. Vilanova también recordaba, como de pasada, la importancia que tenían los restos fósiles humanos para el discernimiento de la cuestión de las migraciones humanas, un asunto que había enfatizado en su discurso inaugural el presidente del Congreso, Armand de Quatrefages, profesor de antropología en el Muséum d'histoire naturelle de París. La cuestión del hombre terciario americano no era ajena a esto:

Deux savants, à qui l'on doit de précieuses découvertes, MM. Ameghino et Whitney, ont même reporté jusqu'aux époques tertiaires l'existence de l'homme américain. Mais, vous savez que cette opinion a été combattue par des hommes d'une valeur égale; et je crois avoir confirmé la manière de voir de ces derniers, par la comparaison des faunes fossiles des pampas du Brésil et des graviers californiens ${ }^{54}$.

Si se demostrara, sin embargo, que la tesis de Ameghino era cierta, y si se pudiera comprobar así mismo que las razas indígenas americanas actualmente existentes se correspondían con aquellos remotos primeros pobladores humanos de América, el postulado de un origen independiente de la humanidad en dicho continente ganaba mucho predicamento. De hecho, una de las cuestiones oficialmente propuestas por el comité organizador del Congreso era si, con pruebas craneológicas, se podía demostrar que las razas indígenas americanas hoy en día existentes eran las mismas que ya habitaban el continente durante el Cuaternario o diluvium ${ }^{55}$. Hay que recordar que Ameghino siempre había considerado la posibilidad de un doble origen del hombre, independiente, en el Viejo y en el Nuevo Mundo ${ }^{56}$. Como ha mostrado Bowler, diversas

53 Vilanova, J. (1892b), L'homme fossile du rio Samborombón. En Congrès International des Américanistes. Compte-rendu de la huitième session tenue a Paris en 1890, pp. 351-352 [facsímil de 1968, Nedeln-Liechtenstein, Kraus Reprint], p. 351. Vilanova tuvo la intención de llevar a París algunas piezas del esqueleto para mostrarlas a sus colegas en el Congreso, pero «Les circonstances épidémiques que nous avons eu à deplorer à Valence m'ont empêché de vous exhiber ces intéressants objets, mais à la prochaine réunion du Congrès en Espagne, je vous promets de vous les montrer»; v. VILANOVA (1892b), p. 352.

54 Quatrefages, A. de (1892), [Discours]. En Congrès International des Américanistes. Compte-rendu de la huitième session tenue a Paris en 1890, pp. 42-55 [facsímil de 1968, Nedeln-Liechtenstein, Kraus Reprint], p. 52.

55 Questions (1892), Questions proposées par le Comité. En Congrès International des Américanistes. Compte-rendu de la huitième session tenue a Paris en 1890, pp. 4-7 [facsímil de 1968, Nedeln-Liechtenstein, Kraus Reprint].

56 SAlgado, L. y AzAR, P.F. (2003), Nuestro lugar entre los primates. Un resumen de las principales ideas de Florentino Ameghino sobre la evolución humana, Saber y Tiempo, 15, pp. 5-18. 
teorías politípicas o poligenistas sobre la evolución humana encontraron predicamento durante los años finales del siglo XIX - el caso de Haeckel es el más conocido, sobre todo por su apelación a la diversidad lingüística-, y aunque crecientemente marginadas por los paleoantropólogos más ortodoxos, todavía continuaban coleando a principios del XX, con defensores como el alemán Hermann Klaatsch (1863-1916), el italiano Giuseppe Sergi (18411936) o el propio Ameghino. En buena medida, tales propuestas partían de asumir la sustantividad específica de las diferencias entre las razas humanas; las diferencias no revelarían sino orígenes diferentes, y la posibilidad actual de interfecundación entre las razas —en realidad, verdaderas especies desde tal enfoque- sería a la postre un fenómeno de convergencia, tras un proceso de evolución paralela. Coherentemente, los poligenistas reclamaban una escala temporal muy larga para la evolución humana ${ }^{57}$. De hecho, Ameghino siempre enfatizaba, junto a la gran antigüedad del poblamiento de las pampas, la diversidad racial americana (puesta de manifiesto tanto biológica como lingüística y culturalmente) ${ }^{58}$. Sin embargo, no debemos pensar que la interpretación estratigráfica de Ameghino se adaptara ad hoc a esa exigencia de tiempo profundo derivada del poligenismo; por el contrario, como muy bien demuestra Podgorny, la cuestión de la antigüedad del hombre en América es una parte más de las controversias acerca del origen y dispersión de los mamíferos en las que se implicó Ameghino tan activamente ${ }^{59}$, y en primer término, también del énfasis en probar que el hombre había sido contemporáneo de faunas extinguidas, algo que ya se había admitido en Europa, pero que costaba todavía de ser asumido en Argentina ${ }^{60}$.

57 BOWLER (1986), pp. 131-146.

58 Podgorny, I. (2001b), La clasificación de los restos arqueológicos en la Argentina, 1880-1940. Primera parte: La diversidad cultural y el problema de la antigüedad del hombre en el Plata, Saber y Tiempo, 12, pp. 5-26.

59 PoDgorny (2005). Del mismo modo, la exclusión de los simios antropomorfos como antepasados del hombre no estaba motivada en el caso de Ameghino por ninguna repelencia a priori, sino de nuevo por coherencia con su interpretación de los fósiles de mamíferos sudamericanos; v. SALGADO y AZAR (2003).

60 Podgorny (2001b). Naturalmente, como en tantos otros casos de la historia de la paleontología humana, también se cruzaban estímulos nacionalistas. V. para el caso argentino, entre otros, BonOMO, M. (2002), El Hombre Fósil de Miramar, Intersecciones en Antropología, 3, pp. 69-85. Casos clásicos de hallazgos paleoantropológicos que se interpretaban desde perspectivas nacionalistas o culturalistas, en TATTERSALL, I. (1995), The Fossil Trail. How We Know What We Think We Know about Human Evolution, New York-Oxford, Oxford University Press. 


\section{UNA POLÉMICA INCONCLUSA}

Los rasgos anómalos o poco frecuentes que mostraba el esqueleto marcaron, sin duda, las expectativas que se depositaron en su estudio y lo convirtieron en un clásico del período fundacional de la paleoantropología. La propia ausencia de descripciones fiables y exhaustivas, y la paralización de los trabajos de montaje de la colección al poco tiempo de su llegada, a consecuencia de la partida precipitada de Enrique de Carles ante la amenaza de la epidemia colérica que se abatió sobre Valencia a mediados de junio del mismo año de 1890 - la última del siglo que afectó a la ciudad ${ }^{61}$ — alimentaron sin duda la especulación. Y así, por si no fuera suficiente con los que efectivamente le atribuían los escritos de Vilanova, al esqueleto se le asignaron otros caracteres singulares, sin base alguna, como la presencia de seis dedos en las manos, de la que hablaban Telesforo de Aranzadi (1860-1945) y Luis de Hoyos Sainz (1868-1951) en el segundo volumen (Etnología) de sus Lecciones de Antropología, que ajustaron al programa de su maestro y mentor, Manuel Antón (1849-1929) ${ }^{62}$, catedrático de Antropología en la Universidad Central y director de la sección de Antropología y Etnografía del Museo de Ciencias Naturales de Madrid desde su fundación en $1883^{63}$. Faltaban, pues, estudios más profundos a partir de los restos, poco accesibles, sin embargo, a causa de los avatares por los que pasó durante aquellos años la colección regalada por José Rodrigo Botet a la ciudad de Valencia ${ }^{64}$. Vilanova, ciertamente, nada más pudo aportar, pues falleció en 1893. El esqueleto, sin embargo, volvió a ser objeto de atención años después, cuando el catedrático de la Universidad de Valencia, Eduardo Boscá Casanoves (1843-1924), asumió la dirección del

61 BÁguena, M.J. (1988), La microbiología. En Las ciencias médicas básicas en la Valencia del siglo XIX, Valencia, Alfons el Magnànim-IVEI-Institut d'Estudis Juan GilAlbert, pp. 197-262.

62 Aranzadi, T. de Hoyos SÁInZ, L. de (1894), Lecciones de Antropología ajustadas al programa del Catedrático Don Manuel Antón. Tomo II. Etnología, Madrid, Imprenta y Litografía de los Huérfanos, pp. 112-113.

63 Esta sección fue transformada en el Museo de Antropología, Etnografía y Prehistoria en 1910; v. Puig-SAMPER, M.A. y GALERA, A. (1983), La Antropología española del siglo XIX, Madrid, CSIC, p. 74. Las ideas evolucionistas de Antón se estudian en PUIG-SAMPER, M.A. (1999), El darwinismo en la antropología española. En GLICK, T.F., RUIZ, R. y PUIGSAMPER, M.A. (eds.), El darwinismo en España e Iberoamérica, Madrid, Universidad Autónoma de México-CSIC-Doce Calles, pp. 152-167.

64 Salinas (2000), passim; Belinchón, PeÑalver, Montoya y Gascó (2009), pp. 35-39. 
montaje del conjunto del legado de José Rodrigo Botet ${ }^{65}$. La polémica, servida desde el mismo momento de su hallazgo, seguiría acompañando al ejemplar también en esa época posterior, como fruto lógico de la continuada polarización en torno a la idea del origen animal de la especie humana por un proceso evolutivo.

Recibido: 5 de diciembre de 2009 .

Aceptado: 20 de julio de 2010.

65 CAtalÁ, J.I. (2004), El desarrollo de una carrera científica en un contexto institucional precario: el caso del naturalista Eduardo Boscá y Casanoves (1843-1924), Cronos, 7 (1), pp. 3-60. Para más detalles, v. CATALÁ, J.I. [en prensa], La polémica sobre el hombre Terciario y su expresión en la Valencia de comienzos del siglo XX, Asclepio. 